\title{
A novel tool for predicting the survival of endoprosthesis used for reconstruction of the knee following tumor resection: a retrospective cohort study
}

Cheng-gang Pang ${ }^{1+}$, Xiong-gang Yang ${ }^{2+}$, Yun-long Zhao ${ }^{1}$, Yan-cheng Liu ${ }^{3}$ and Yong-cheng $\mathrm{Hu}^{3^{*}}$

\begin{abstract}
Background: Prosthesis-related complications, after knee reconstruction with endoprosthesis during operation for tumors around the knee, remain an unresolved problem which necessitate a revision or even an amputational surgery. The purpose of the current study was to identify significant risk factors associated with implant failure, and establish a novel model to predict survival of the prosthesis in patients operated with endoprostheses for tumor around knee.

Methods: We retrospectively reviewed the clinical database of our institution for patients who underwent knee reconstruction due to tumors. A total of 203 patients were included, including 123 males (60.6\%) and 80 (39.4\%) females, ranging in age from 14 to 77 years (mean: $34.3 \pm 17.3$ years). The cohort was randomly divided into training $(n=156)$ and validation $(n=47)$ samples. Univariable COX analysis was used for initially identifying potential independent predictors of prosthesis survival with the training group $(p<0.150)$. Multivariate COX proportional hazard model was selected to identify final significant prognostic factors. Using these significant predictors, a graphic nomogram, and an online dynamic nomogram were generated for predicting the prosthetic survival. Cindex and calibration curve were used for evaluate the discrimination ability and accuracy of the novel model, both in the training and validation groups.
\end{abstract}

Results: The 1-, 5-, and 10-year prosthetic survival rates were 94.0, 90.8, and 83.0\% in training sample, and 96.7, 85.8, and $76.9 \%$ in validation sample, respectively. Anatomic sites, length of resection and length of prosthetic stem were independently associated with the prosthetic failure according to multivariate COX regression model $(p<0.05)$. Using these three significant predictors, a graphical nomogram and an online dynamic nomogram model were generated. The C-indexes in training and validation groups were 0.717 and 0.726 respectively, demonstrating favourable discrimination ability of the novel model. And the calibration curve at each time point showed favorable consistency between the predicted and actual survival rates in training and validation samples.

\footnotetext{
* Correspondence: huyongchengtianjin@163.com

${ }^{+}$Cheng-gang Pang and Xiong-gang Yang contributed equally to this work.

${ }^{3}$ Department of Bone Tumor of Tianjin Hospital, Tianjin 300211, China

Full list of author information is available at the end of the article
}

(c) The Author(s). 2021 Open Access This article is licensed under a Creative Commons Attribution 4.0 International License, which permits use, sharing, adaptation, distribution and reproduction in any medium or format, as long as you give appropriate credit to the original author(s) and the source, provide a link to the Creative Commons licence, and indicate if changes were made. The images or other third party material in this article are included in the article's Creative Commons licence, unless indicated otherwise in a credit line to the material. If material is not included in the article's Creative Commons licence and your intended use is not permitted by statutory regulation or exceeds the permitted use, you will need to obtain permission directly from the copyright holder. To view a copy of this licence, visit http://creativecommons.org/licenses/by/4.0/. The Creative Commons Public Domain Dedication waiver (http://creativecommons.org/publicdomain/zero/1.0/) applies to the data made available in this article, unless otherwise stated in a credit line to the data. 
Conclusions: The length of resection, anatomical location of tumor, and length of prosthetic stem were significantly associated with prosthetic survival in patients operated for tumor around knee. A user-friendly novel online model model, with favorable discrimination ability and accuracy, was generated to help surgeons predict the survival of the prosthesis.

Keywords: Limb salvage, Prognostic factor, Tumor endoprostheses, Nomogram

\section{Background}

The distal femur and the proximal tibia are common sites for primary and metastatic bone tumor [1]. Amputation was the traditional surgical treatment for musculoskeletal sarcomas of the extremities, with the aim of saving the patients' life. With the simultaneous improvement on the understanding of the biology and staging of tumors, reconstructive techniques, and effective adjuvant chemotherapy, however, limb salvage surgery has replaced the amputation as the predominated treatment choice for more than $90 \%$ of patients with a primary malignancy on the knee [2-4].

Because of the unique biological inherent properties of the tumor, the complex anatomic features of the knee and problems associated with extensor reconstruction, tumors arising around the knee pose a unique set of challenges in the management of soft tissues and the restoration of limb length and joint kinetics. The options for reconstruction after resection of a tumor around the knee joint include implantation of a prosthesis, osteoarticular allograft, allograft-prosthesis composite, recycled autologous bone graft, arthrodesis with intercalary bone grafting or conversion to a rotationplasty [5]. Among these methods, tumor prosthesis offers the advantages of convenience, early mobilization, and weight bearing capability, and it allows the early introduction of postoperative adjuvant therapy. Furthermore, there are no differences in survival rates between limb-salvage and ablative surgery [6-8].

Although advances in materials and implant design have occurred over the past three decades, complications and failures of these devices remain high compared to other arthroplasty procedures [9-11]. Prosthesis-related complications, including infection, aseptic loosening, dislocation, recurrence of the tumor, joint stiffness or contracture, instability of components, and implant mechanical weaknesses, remain an unresolved problem which necessitate a revision or even an amputational surgery [12-14]. High rate of prosthesis-related failure indicates that tumor endoprostheses need to be further studied, and improvements in surgical technique and component design are required. To guide the treatments selection and decision making, it may be crucial to clarify the prognostic factors that significantly predict the survival of prosthesis used for reconstructing the knee operated for tumors. Until now few studies have analyzed the prognostic effect of patients' and operationrelated characteristics.

The nomogram is a type of easy-to-use predicting model, which transforms traditional statistical predictive models into visualized probability estimates tailored to each patient. Using this model, one could be provided with continuous survival probabilities at several time points that predicted for an individual patient. What is more, the nomogram could be further transformed into a webpage based predicting widget, easily providing a predicted Kaplan-Meier survival curve, and survival rate at each time point.

Thus, the purpose of this study was (1) to evaluate the clinical and functional outcomes of patients who underwent a limb salvage surgery for tumors around the knee, (2) to identify prognostic factors significantly associated with implant failure, (3) and to develop a validated nomogram model as well as a webpage based predicting tool.

\section{Methods}

This study was conducted according to the Transparent Reporting of a Multivariable Prediction Model for Individual Prognosis or Diagnosis (TRIPOD) statement [15], and reported according to the Strengthening the Reporting of Observational Studies in Epidemiology (STROBE) Statement (Available in Additional file 1).

\section{Patients inclusion}

In accordance with the Declaration of Helsinki and upon the attained ethical approval from the hospital ethics committee, information of 297 consecutive patients with neoplastic disease around the knee who were treated with tumor resection and subsequent endoprosthetic reconstruction between April 1995 and August 2018 in two individual research centers were retrospectively reviewed for potential eligibility.

Patients would be included following the inclusion criteria: (1) age $\geq 14$ years at the time of surgery; (2) bone tumors located around the knee; (3) limb-salvage or ablative surgery. The initial diagnosis was made based on pre-operative radiographs (X ray, magnetic resonance imaging [MRI] or computed tomography), and consequently confirmed by core needle biopsy or by open biopsy and pathological examination. Patients with reconstructed knee for medical conditions other than bone 
tumor, patients lost to follow-up, or patients with incomplete medical document were excluded.

\section{Surgical treatment}

All patients indicative for limb-salvage surgery were evaluated systemically on the lesion size, preoperative planning of the level and optimal types of prostheses. The dimensions of the tumor and boundaries were measured by a combination of total leg-length radiographs and cross-sectional imaging, including MRI or 3D Multi-Slice Computerized Tomography (3D MSCT). With the completion of imaging materials and histology diagnosis, patients were categorized to a surgical stage according to Musculoskeletal Tumor Society (MSTS) classification [16] and received neoadjuvant chemotherapy on protocol when applicable. After resection of the tumor, reconstruction was performed using a cemented metal endoprosthesis (custom/modular). During the early time of the surgery, custom implants (fixed/hinged) were used in 88 patients. Modular implants featuring a rotating hinge mechanism were subsequently implanted in the remaining 63 patients. The surgical resection and reconstruction were performed by two senior professors, whose members of the team were orthopedic surgeons with extensive experience in the field the knee arthroplasty procedures, following the generally accepted oncologic principles of obtaining a wide surgical margin. Excision was performed through a medial or lateral parapatellar approach. Frozen section analysis of the intramedullary canal contents at the resection site was performed intraoperatively to ensure a negative marrow margin. An intraoperative radiograph was also performed to confirm that the fine line force of the knee was obtained for all the patients. We then performed a soft tissue reconstruction for each individual to achieve muscular coverage of the implants and to restore function of the knee.

Post-operative management mainly focused on prophylaxis of incision infection and application of antithrombotics and analgesics. Intravenous antibiotic prophylaxis was maintained until the wound drains were removed. Mobilization commenced on the second day postoperatively with the assistance of a walker with the purpose of preventing thrombogenesis or development of a infection in the urinary systems.

\section{Post-operative rehabilitation protocol}

In order to obtain the maximum function of the knee postoperatively, detailed procedures were described as follows. Firstly, immediate weight bearing assisted with the hinged brace around the knee for all patients was permitted due to the stability of the cemented implants and the stability of reconstructed knee. A continuous passive motion (CPM) apparatus was used under professional rehabilitation therapist's guidance and supervision on the first day post-operatively and continued until discharge. Extra attention was paid for patients with reconstructions of the extensor mechanism, whose motion was commenced from $-5^{\circ}$ to $10^{\circ}$ extension to $30^{\circ}$ to $45^{\circ}$ flexion and gradually increased to greater than $90^{\circ}$ flexion before discharge. When rehabilitation was executed, patients were administrated appropriate anodyne, which allowed them an indolent restoration.

\section{Recorded variables}

The patients were required to be interviewed every 3 weeks for the first 3 months after surgery, then on a quarterly basis for 3 years, semiannually for an additional 2 years, and then annually. The medical records, radiographs and pathologic records, operation details, information about adjuvant oncological therapies, and oncologic outcomes were reviewed. We recorded the following variables as the potential prognostic factors: age at operation, sex, body mass index (BMI), tumor types (divided into borderline tumor, malignant primary tumor, and metastatic bone tumor), operation related complications within 6 months, adjuvant chemotherapy/ radiotherapy, pathological fracture, primary/ revision reconstruction, anatomical location (proximal tibia or distal femur), site of knee (left or right), bleeding volume, operation time, bone transplantation, prosthesis type (custom or modular), prosthesis motion mode (rotational or fixed), length of prosthetic stem, diameter of prosthetic stem, material of prosthesis (titanium or vatallium), and length of resection.

The outcome variable was prosthesis survival, which was defined as the time interval between operation and prosthesis failure (any cause that required replacement of the components of the prosthesis).

\section{Statistical analysis}

The included patients were randomly divided into training sample and validation sample with a ratio of 7:3. The training sample was used for model establishing and internal validation, while the validation sample was used for external validation. The continuous variables, including the age, BMI, length of prosthetic stem, diameter of prosthetic stem, length of osteotomy, operation time, and bleeding volume, were transformed into dichotomous variable using the cutoff point detected with the method of running log rank test $[17,18]$. The distribution of the patients according to each prognostic factor was described as mean \pm SD or percentage. KaplanMeier survival curve was used to describe the overall patients' survival and prosthetic survival, in training and validation samples.

Univariate analysis using COX proportional hazards model was performed to initially identify the potential 
significance of each prognostic variable on predicting the prosthetic survival. All of the variables demonstrated to be significantly or marginally significantly $(p<0.15)$ associated with prosthetic survival were included in the multivariable COX analysis. Kaplan-Meier survival curves were generated for all prognostic factors involved in multivariable analysis. Hazard ratio (HR) and confidence interval $(95 \% \mathrm{CI})$ were selected as the effect size for both univariate and multivariate COX model. A forest plot was generated to display the result of multivariate analysis.

Basing on the significant variables screened by multivariate COX model, a novel nomogram was plotted, to graphically provide continuous survival rates at several time points and the median survival time of prosthesis. C-index and calibration curve were used to evaluate the discrimination ability and accuracy of the nomogram respectively. Finally, after fitting of a new COX model using the variables involved in the graphical nomogram, a webpage-based dynamic nomogram, which could provide predicted survival curve and survival rate at any time point as wanted, was established.

All analyses have been performed with program of $R$ language (Foundation for Statistical Computing, Vienna, Austria). The univariable and multivariable COX models were fitted using the R package "survival". The graphical nomogram and the online dynamic nomogram were generated with the packages "rms" and "DynNom". Level of statistical significance was set at $P<0.05$.

\section{Results}

\section{Patients' baseline characteristics}

A total of 203 patients (156 divided into the training sample and 47 divide into the validation sample) were eligible for final inclusion according to the inclusion and exclusion criteria. The baseline characteristics is shown in the Table 1. Among these patients, there were 99 males (63.46\%) and 53 (36.54\%) females, and 24 male $(51.06 \%)$ and 23 female in the training and validation samples, respectively. The mean age was $35.31 \pm 17.54$ and $31.09 \pm 16.17$ years in the training and validation samples at the time of surgery. The distal femur $(n=99$, $63.46 \%)$ was more common than proximal tibia $(n=57$, $36.54 \%$ ) concerning the involved anatomical location. The distribution of the tumor histology is presented in Fig. 1, showing that malignant primary tumor (osteosarcoma, 72; malignant fibrous histiotoma, 9; chondrosarcoma, 6; leiomyosarcoma, 3; synoviosarcoma, 2) was the predominated tumor type, followed by borderline tumor (giant cell tumor of bone, 53; fibrous histiotoma, 3) and malignant metastatic tumor.

Within 6 months post-operatively, a total of 26 (16.67\%) and 7 (14.89\%) patients were encountered with operation related complications, in the training and validation groups. The major complications leading to implant failure were aseptic loosening in 26 out of 20 patients $(20 / 132,15.1 \%)$, followed by superficial or periprosthetic infection (16), local recurrence or metastases or both (12), periprosthetic or prosthetic fracture (7), wound healing disorders (4), joint instability or flexion contracture in two (2), dislocation of the prosthesis in one patients (3). Four patients developed nonprosthesisrelated complications include peroneal nerve palsy (2), others (3). Local relapse arose in $16(10.26 \%)$ patients and $5(10.64 \%)$ patients during the follow-up.

The Kaplan-Meier survival curves for the patients' overall survival and prosthesis survival are shown in Fig. 2. The overall patients' survival at 12,60 , and 120 months were 94.0, 90.8 and $83.0 \%$, and 95.7, 92.8 and $83.9 \%$ in training and validation groups, respectively. The prosthesis survival at $12,60,120$, and 180 months were 96.7, 85.8, 76.9 and 44.0\%, and 95.7, 82.9, 67.5 and $45.0 \%$ in training and validation groups, respectively.

\section{Results of univariate and multivariate COX analyses}

Figure 3 shows the results of running log-rank test for the continuous predictors, presenting the optimal cut-off points to convert these factors into categorical variables. The results of univariate COX analysis are shown in Table 2, and the Kaplan-Meier survival curves for the significant and marginally significant $(p<0.15)$ prognostic factors are presented in Fig. 4. As a result, anatomical location at distal femur (HR $=0.412,95 \%$ CI: $0.180 \sim 0.945$, $P=0.036)$, fixed prosthetic motion mode $(\mathrm{HR}=2.336$, 95\%CI: $1.134 \sim 4.812, P=0.021$ ), and length of resection ( $>=10.4 \mathrm{~cm} ; \mathrm{HR}=8.959,95 \% \mathrm{CI}: 3.767 \sim 21.310, P<0.001$ ) were significantly associated with increased implant failure, while BMI (HR $=2.555,95 \% \mathrm{CI}$ : $0.715 \sim 9.135, P=0.149$ ), operation related complications (HR $=1.877,95 \%$ CI: 0.918 $\sim 3.840, P=0.085$ ), custom/ modular prosthesis (HR = 2.244, 95\%CI: $0.957 \sim 5.257, P=0.063)$, and length of prosthetic stem $(\mathrm{HR}=0.578,95 \% \mathrm{CI}: 0.287 \sim 1.165, P=0.125)$ were demonstrated to be marginally associated with the survival of implant.

The forest plot in Fig. 5 shows the effect sizes of multivariate analysis, presenting that anatomical location (HR $=0.42,95 \%$ CI: $0.20 \sim 0.89, P=0.024$ ), length of prosthetic stem (HR $=0.44,95 \% \mathrm{CI}: 0.19 \sim 0.99, P=0.048)$ and length of bone resection (HR $=11.08,95 \% \mathrm{CI}: 3.34 \sim 36.78$, $P<0.001)$ remained to be statistically significant prognostic factors for prosthetic survival.

\section{Establishing and validation of nomogram model}

Basing on the significant prognostic factors screened by multivariate COX model, a graphical predicting nomogram model was developed, to calculate the predicted prosthetic survival probabilities at 1,5 , and 10 years 
Table 1 Summary of patients' baseline characteristics

\begin{tabular}{|c|c|c|c|c|}
\hline \multirow{2}{*}{$\begin{array}{l}\text { Variables } \\
\text { Age }\end{array}$} & \multicolumn{2}{|c|}{ Training sample } & \multicolumn{2}{|c|}{ Validation sample } \\
\hline & & & & \\
\hline Average $(\mathrm{n} /$ mean $\pm \mathrm{SD})$ & 156 & $35.3 \pm 21.1$ & 47 & $31.1 \pm 16.2$ \\
\hline$<58$ years $(\mathrm{n} / \%)$ & 132 & 84.62 & 42 & 89.36 \\
\hline$\geq 58$ years $(n / \%)$ & 24 & 15.38 & 5 & 10.64 \\
\hline \multicolumn{5}{|l|}{$\operatorname{Sex}(n / \%)$} \\
\hline Male & 99 & 63.46 & 24 & 51.06 \\
\hline Female & 57 & 36.54 & 23 & 48.94 \\
\hline \multicolumn{5}{|l|}{ BMI } \\
\hline average $(\mathrm{n} /$ mean $\pm \mathrm{SD})$ & 41 & $25.4 \pm 3.9$ & 11 & $27.8 \pm 3.9$ \\
\hline$<26.8(n / \%)$ & 26 & 63.41 & 4 & 36.36 \\
\hline$\geq 26.8(n / \%)$ & 15 & 36.59 & 7 & 63.64 \\
\hline \multicolumn{5}{|l|}{ Tumor types (n/\%) } \\
\hline Borderline tumor & 56 & 35.90 & 16 & 34.00 \\
\hline Malignant primary tumor & 92 & 58.97 & 29 & 61.70 \\
\hline Malignant metastatic tumor & 8 & 5.13 & 2 & 4.30 \\
\hline \multicolumn{5}{|c|}{ Operation related complications (n/\%) } \\
\hline No & 130 & 83.33 & 40 & 85.11 \\
\hline Yes & 26 & 16.67 & 7 & 14.89 \\
\hline \multicolumn{5}{|c|}{ Adjuvant chemotherapy/ radiotherapy (n/\%) } \\
\hline No & 84 & 53.85 & 24 & 52.17 \\
\hline Yes & 72 & 46.15 & 22 & 47.83 \\
\hline \multicolumn{5}{|l|}{ Pathological fracture $(n / \%)$} \\
\hline No & 118 & 75.64 & 38 & 80.85 \\
\hline Yes & 38 & 24.36 & 9 & 19.15 \\
\hline \multicolumn{5}{|c|}{ Primary/ revision reconstruction (n/\%) } \\
\hline Primary reconstruction & 112 & 71.79 & 36 & 76.60 \\
\hline Revision reconstruction & 44 & 28.21 & 11 & 23.40 \\
\hline \multicolumn{5}{|l|}{ Anatomical location $(\mathrm{n} / \%)$} \\
\hline Distal femur & 99 & 63.46 & 31 & 65.96 \\
\hline Proximal tibia & 57 & 36.54 & 16 & 34.04 \\
\hline \multicolumn{5}{|l|}{ Site of knee (n/\%) } \\
\hline Left & 85 & 54.49 & 25 & 53.19 \\
\hline Right & 71 & 45.51 & 22 & 46.81 \\
\hline \multicolumn{5}{|l|}{ Bleeding volume (n/\%) } \\
\hline average $(\mathrm{n} /$ mean $\pm \mathrm{SD})$ & 144 & $790.4 \pm 602.6$ & 34 & $597.7 \pm 389.1$ \\
\hline$<1000 \mathrm{ml}$ & 97 & 67.36 & 24 & 70.59 \\
\hline$>=1000 \mathrm{ml}$ & 47 & 32.64 & 10 & 29.41 \\
\hline \multicolumn{5}{|l|}{ Operation time } \\
\hline average $(\mathrm{n} /$ mean $\pm \mathrm{SD})$ & 134 & $177.0 \pm 54.3$ & 43 & $166.2 \pm 40.1$ \\
\hline$<210 \min (\mathrm{n} / \%)$ & 101 & 75.37 & 35 & 81.40 \\
\hline$>=210 \min (n / \%)$ & 33 & 24.63 & 8 & 18.60 \\
\hline \multicolumn{5}{|l|}{ Bone transplantation $(\mathrm{n} / \%)$} \\
\hline No & 142 & 91.03 & 42 & 89.36 \\
\hline Yes & 14 & 8.97 & 5 & 10.64 \\
\hline
\end{tabular}


Table 1 Summary of patients' baseline characteristics (Continued)

\begin{tabular}{|c|c|c|c|c|}
\hline \multirow{2}{*}{$\begin{array}{l}\text { Variables } \\
\text { Custom/ modular prosthesis ( } n / \%)\end{array}$} & \multicolumn{2}{|c|}{ Training sample } & \multicolumn{2}{|c|}{ Validation sample } \\
\hline & & & & \\
\hline Custom & 91 & 58.33 & 31 & 65.96 \\
\hline Modular & 65 & 41.67 & 16 & 34.04 \\
\hline \multicolumn{5}{|c|}{ Prosthesis motion mode $(\mathrm{n} / \%)$} \\
\hline Rotational & 137 & 87.82 & 40 & 85.11 \\
\hline Fixed & 19 & 12.18 & 7 & 14.89 \\
\hline \multicolumn{5}{|l|}{ Length of prosthetic stem } \\
\hline average $(n /$ mean $\pm S D)$ & 107 & $140.4 \pm 23.8$ & 43 & $136.3 \pm 23.6$ \\
\hline$<144 \mathrm{~mm}(\mathrm{n} / \%)$ & 66 & 61.68 & 25 & 58.14 \\
\hline$>=144$ mm (n/\%) & 41 & 38.32 & 18 & 41.86 \\
\hline \multicolumn{5}{|c|}{ Diameter of prosthetic stem } \\
\hline average $(n /$ mean $\pm S D)$ & 121 & $12.1 \pm 1.7$ & 43 & $11.9 \pm 1.7$ \\
\hline$<12 \mathrm{~mm}(\mathrm{n} / \%)$ & 46 & 38.02 & 19 & 44.19 \\
\hline$>=12 \mathrm{~mm}(\mathrm{n} / \%)$ & 75 & 61.98 & 24 & 55.81 \\
\hline \multicolumn{5}{|c|}{ Material of prosthesis (n/\%) } \\
\hline Titanium & 105 & 69.08 & 31 & 68.89 \\
\hline Vatallium & 47 & 30.92 & 14 & 31.11 \\
\hline \multicolumn{5}{|l|}{ Length of resection } \\
\hline average $(\mathrm{n} /$ mean $\pm S D)$ & 150 & $12.8 \pm 3.6$ & 47 & $12.7 \pm 3.7$ \\
\hline$<10.4 \mathrm{~cm}(\mathrm{n} / \%)$ & 40 & 26.67 & 14 & 29.79 \\
\hline$>=10.4 \mathrm{~cm}(\mathrm{n} / \%)$ & 110 & 73.33 & 33 & 70.21 \\
\hline
\end{tabular}

Footnote: Abbreviations: $B M I$ body mass index; $S D$ standard deviation

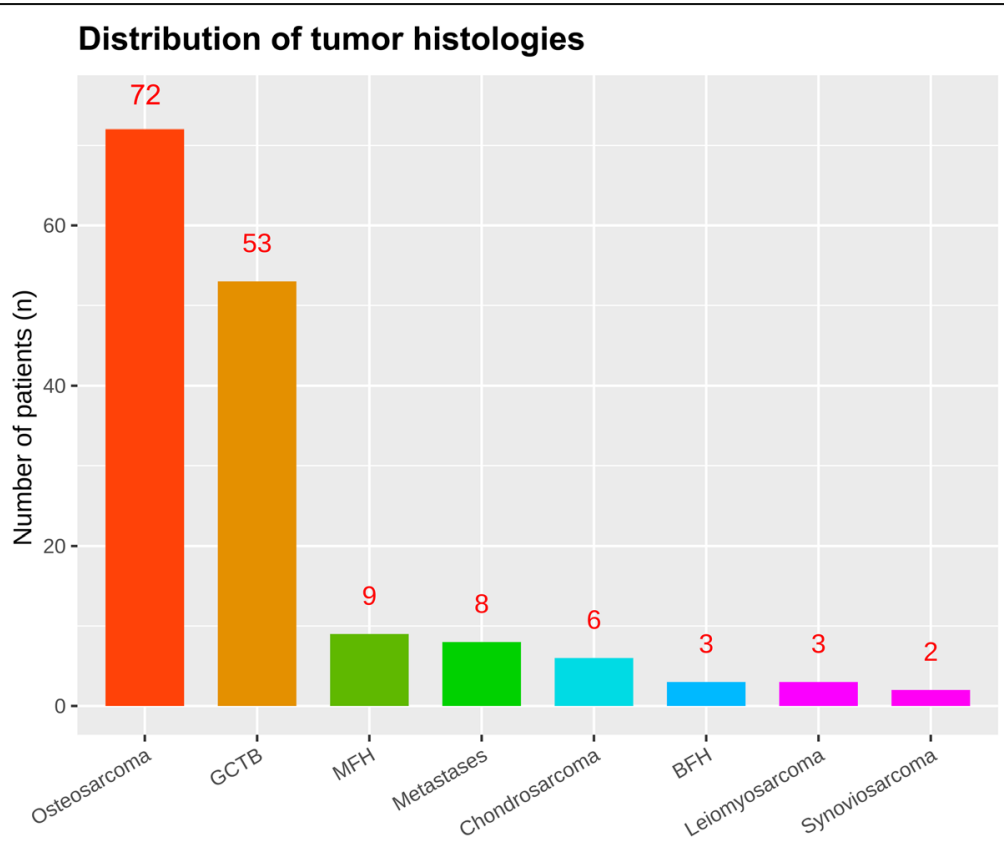

Fig. 1 Distribution of the tumor histology. Abbreviations: GCTB, giant cell tumor of bone; MFH, malignant fibrous histiotoma; BFH, borderline fibrous histiotoma 


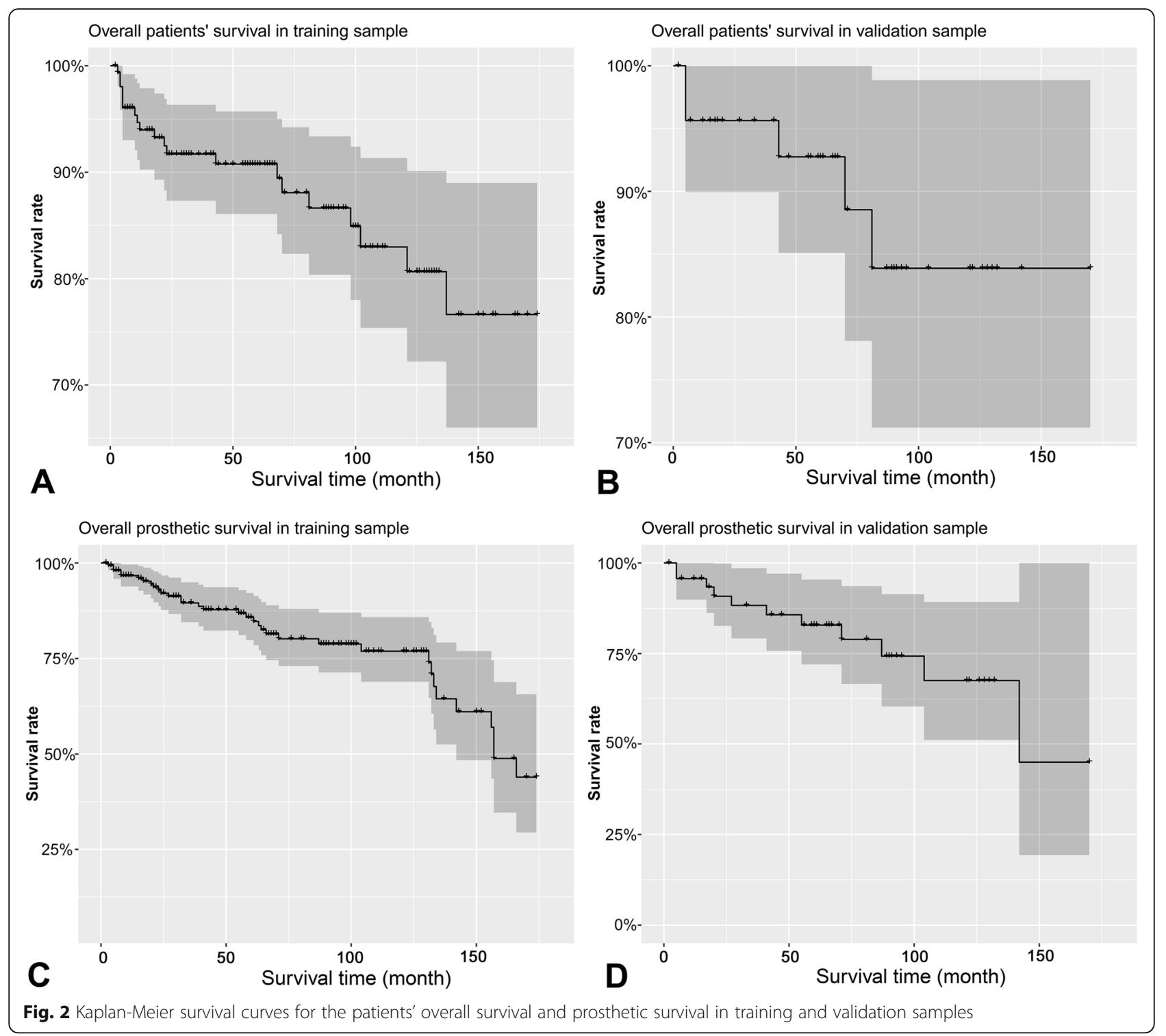

post-operatively, as well as the median survival time (Fig. 6).

The C-indexes were 0.717 (95\%CI: $0.497 \sim 0.937)$ and 0.726 (95\%CI: $0.244 \sim 1.208$ ) for the training and validation samples respectively, demonstrating that the newly established nomogram possesses favorable discrimination ability. The calibration curves at 12, 60 and 120 months for the two samples are displayed in Fig. 7. Generally, favorable consistencies between the predicted and actual survival were presented, indicating satisfactory accuracy of the novel predicting model.

To facilitate the usage of our novel predicting model, a web link (https://hellonihao.shinyapps.io/PangCG_ DynNomapp/) was generated to automatically calculate the prosthetic survival online for each individual patient. The predicted survival curve, forest plot presenting survival probability, and numeric summary table would be output, after selecting of the patients' characteristics and clicking on the button "Predict". The survival probability at any time point could be obtained by dragging the sliderbar "time".

\section{Case presentation}

Figure 8 and Fig. 9 show a case of patient who was operated for bone tumor locates at distal femur and reconstructed with a prosthesis that was more than $14.4 \mathrm{~cm}$ on length of stem, and more than $10.4 \mathrm{~cm}$ of bone was resected during tumorectomy. Using the graphical nomogram, only approximate survival rates could be read on the plot by drawing a vertical line through the total point. While, through the webpage-based dynamic nomogram, the detailed prosthetic survival probabilities at 12, 60 and 120 months could be automatically calculated, which is shown to be $0.890,0.305$ and 0.068 , respectively. 

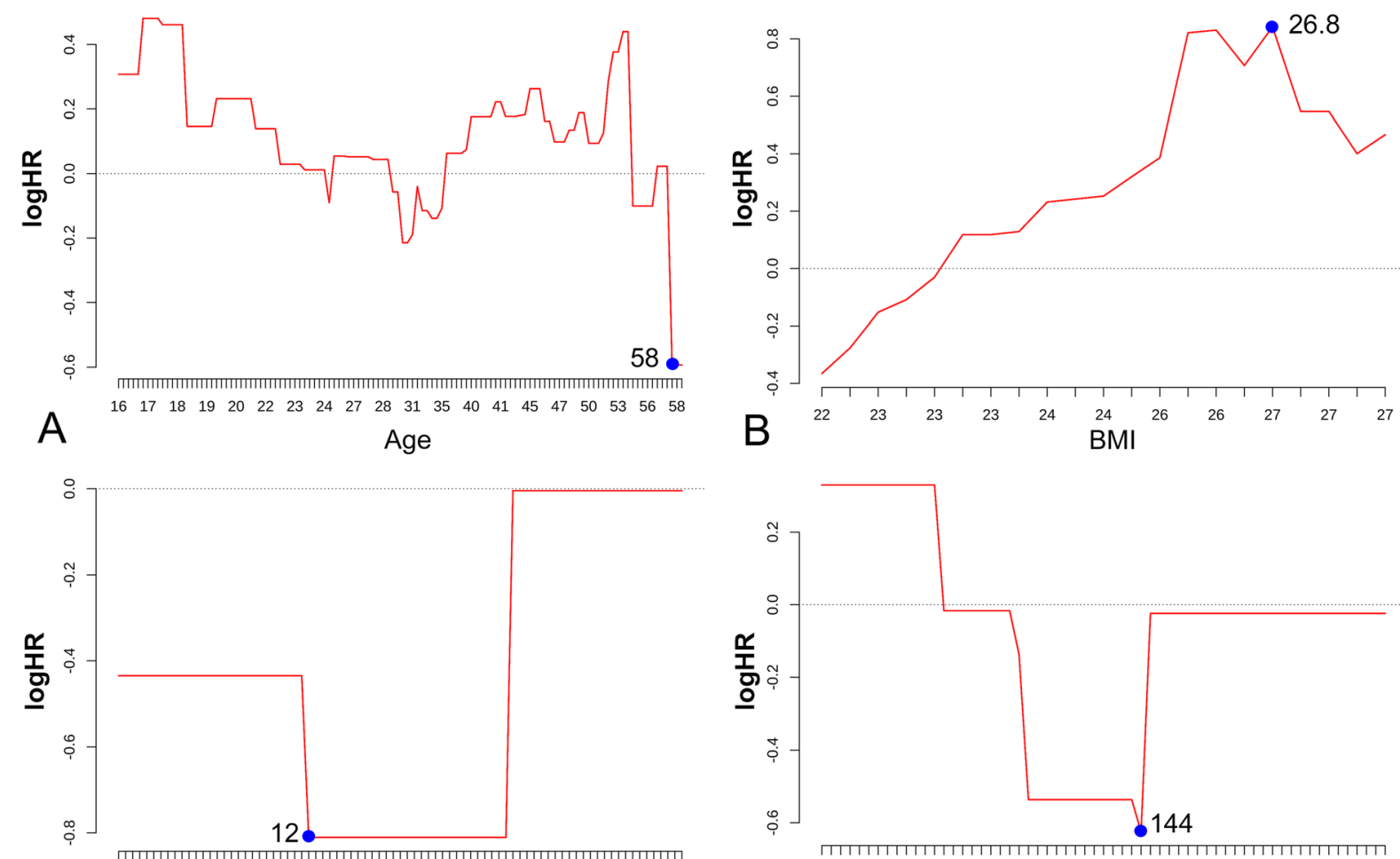

C $\quad \begin{array}{lllllllllllllllll}11 & 11 & 11 & 11 & 11 & 11 & 12 & 12 & 12 & 12 & 12 & 12 & 13 & 13 & 13 & 13 & 13\end{array}$ Diameter $(\mathrm{mm})$

$\begin{array}{lllllllllllllllll}127 & 127 & 127 & 127 & 130 & 130 & 140 & 140 & 140 & 150 & 150 & 150 & 150 & 150 & 150 & 150\end{array}$
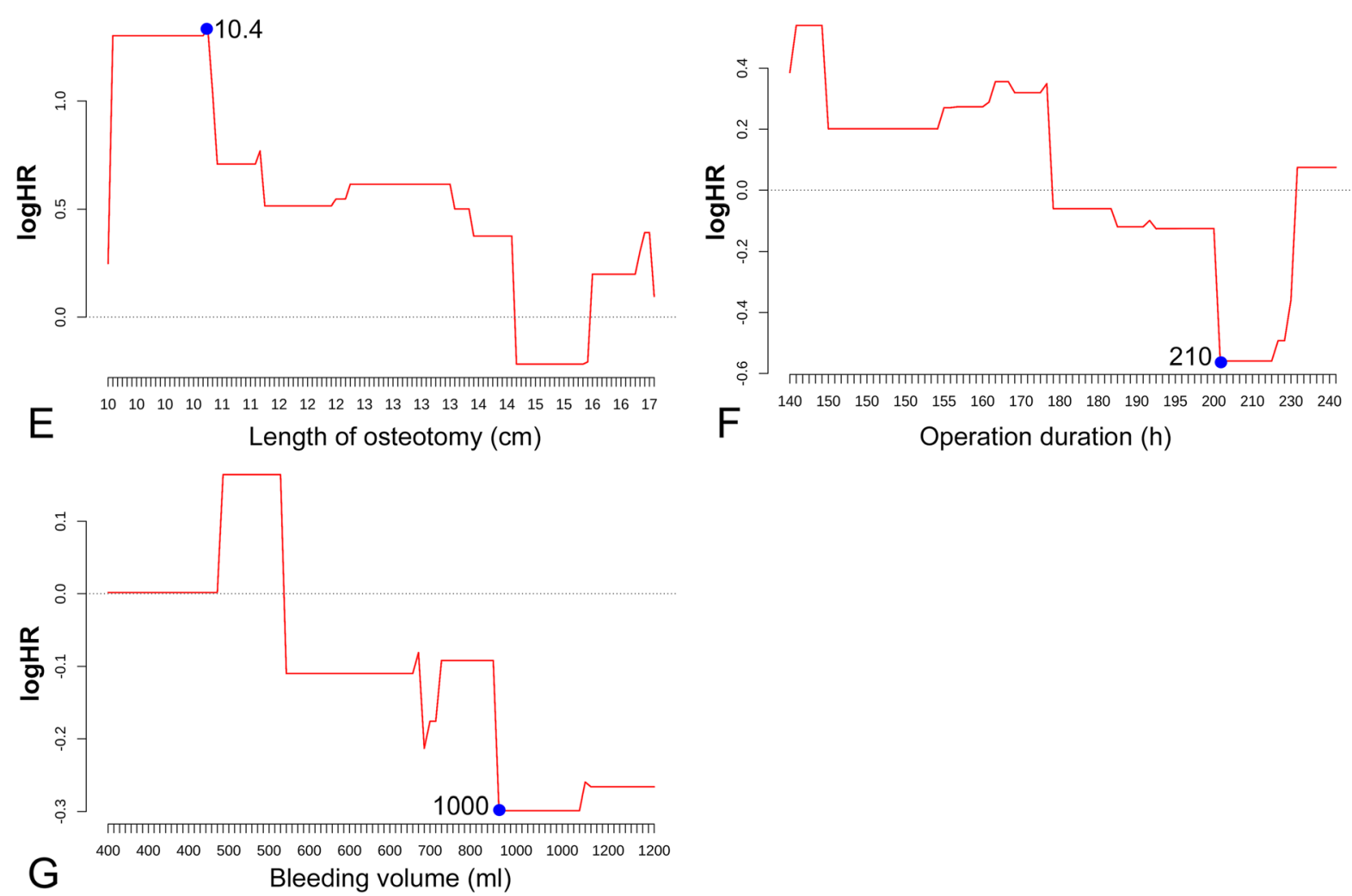

Fig. 3 Results of running log-rank tests to detect the optimal cutoff points for continuous prognostic factors of implant survival, including age $(\mathbf{A})$, BMI (B), stem diameter $(\mathbf{C})$, stem length $(\mathbf{D})$, length of osteotomy $(\mathbf{E})$, operation duration $(\mathbf{F})$ and bleeding volume $(\mathbf{G})$ 
Table 2 Results of univariate COX analysis

\begin{tabular}{|c|c|c|c|c|c|}
\hline \multirow[t]{2}{*}{ Variables } & \multicolumn{5}{|c|}{ Univariate COX analysis } \\
\hline & & HR & $\mathrm{LCl}$ & $\mathrm{UCl}$ & $P$ value \\
\hline \multicolumn{6}{|l|}{ Age } \\
\hline$<58$ years & 1 & & & & \\
\hline$\geq 58$ years & 1.021 & & 0.358 & 2.913 & 0.969 \\
\hline \multicolumn{6}{|l|}{ Sex } \\
\hline Male & 1 & & & & \\
\hline Female & 0.937 & & 0.463 & 1.898 & 0.857 \\
\hline \multicolumn{6}{|l|}{ BMI } \\
\hline$<26.8$ & 1 & & & & \\
\hline$\geq 26.8$ & 2.555 & & 0.715 & 9.135 & 0.149 \\
\hline \multicolumn{6}{|l|}{ Tumor types } \\
\hline Borderline tumor & 1 & & & & \\
\hline Malignant primary tumor & 0.718 & & 0.358 & 1.438 & 0.350 \\
\hline Malignant metastatic tumor & 0.000 & & 0.000 & Inf & 0.997 \\
\hline \multicolumn{6}{|c|}{ Operation related complications } \\
\hline No & 1 & & & & \\
\hline Yes & 1.877 & & 0.918 & 3.840 & 0.085 \\
\hline \multicolumn{6}{|c|}{ Adjuvant chemotherapy/ radiotherapy } \\
\hline No & 1 & & & & \\
\hline Yes & 1.058 & & 0.545 & 2.057 & 0.867 \\
\hline \multicolumn{6}{|l|}{ Pathological fracture } \\
\hline No & 1 & & & & \\
\hline Yes & 1.479 & & 0.731 & 2.993 & 0.277 \\
\hline \multicolumn{6}{|c|}{ Primary/ revision reconstruction } \\
\hline Primary reconstruction & 1 & & & & \\
\hline Revision reconstruction & 1.038 & & 0.514 & 2.096 & 0.918 \\
\hline \multicolumn{6}{|l|}{ Anatomical location } \\
\hline Distal femur & 1 & & & & \\
\hline Proximal tibia & 0.412 & & 0.180 & 0.945 & $0.036^{*}$ \\
\hline \multicolumn{6}{|l|}{ Site of knee } \\
\hline Left & 1 & & & & \\
\hline Right & 0.878 & & 0.445 & 1.730 & 0.706 \\
\hline \multicolumn{6}{|l|}{ Bleeding volume } \\
\hline$<1000 \mathrm{ml}$ & 1 & & & & \\
\hline$>=1000 \mathrm{ml}$ & 0.906 & & 0.423 & 1.941 & 0.800 \\
\hline \multicolumn{6}{|l|}{ Operation time } \\
\hline$<210 \min$ & 1 & & & & \\
\hline$>=210 \mathrm{~min}$ & 0.881 & & 0.368 & 2.105 & 0.775 \\
\hline \multicolumn{6}{|l|}{ Bone transplantation } \\
\hline No & 1 & & & & \\
\hline Yes & 1.506 & & 0.622 & 3.645 & 0.364 \\
\hline \multicolumn{6}{|l|}{ Custom/ modular prosthesis } \\
\hline Custom & 1 & & & & \\
\hline Modular & 2.244 & & 0.957 & 5.257 & 0.063 \\
\hline
\end{tabular}


Table 2 Results of univariate COX analysis (Continued)

\begin{tabular}{|c|c|c|c|c|c|}
\hline \multirow[t]{2}{*}{ Variables } & \multicolumn{5}{|c|}{ Univariate COX analysis } \\
\hline & & HR & LCl & UCl & $P$ value \\
\hline \multicolumn{6}{|c|}{ Prosthesis motion mode } \\
\hline Rotational & 1 & & & & \\
\hline Fixed & 2.336 & & 1.134 & 4.812 & $0.021 *$ \\
\hline \multicolumn{6}{|c|}{ Length of prosthetic stem } \\
\hline$<144 \mathrm{~mm}$ & 1 & & & & \\
\hline$>=144 \mathrm{~mm}$ & 0.578 & & 0.287 & 1.165 & 0.125 \\
\hline \multicolumn{6}{|c|}{ Diameter of prosthetic stem } \\
\hline$<12 \mathrm{~mm}$ & 1 & & & & \\
\hline$>=12 \mathrm{~mm}$ & 0.618 & & 0.289 & 1.323 & 0.215 \\
\hline \multicolumn{6}{|c|}{ Material of prosthesis } \\
\hline Titanium & 1 & & & & \\
\hline Vatallium & 1.128 & & 0.370 & 3.411 & 0.832 \\
\hline \multicolumn{6}{|c|}{ Length of resection } \\
\hline$<10.4 \mathrm{~cm}$ & 1 & & & & \\
\hline$>=10.4 \mathrm{~cm}$ & 8.959 & & 3.767 & 21.310 & $<0.001^{* *}$ \\
\hline
\end{tabular}

\section{Discussion}

Multimodality limb salvage therapy has replaced amputation as the preferred form of treatment for primary musculoskeletal tumors primarily owing to improvements in adjuvant and neo-adjuvant therapy, as well as advances in imaging and diagnostic modalities [2-4]. After the resection of bone and soft tissue tumors, reconstruction of the resulting defects was challenging because of the unique anatomic features of the knee. Limb-salvage surgery for malignant bone tumors must be successful in three different respects, that is, the cure of oncology, the durability of prostheses and the satisfactory of the function in the limbs. Following reconstruction of the operated knee, arising of complications in implants was not uncommon, and the prosthetic failure has always been regarded as a major event causing serious adverse effect on the patients' overall survival, lower limb function and the quality of life, for these tumor patients. Thus, it is necessary to figure out the significant prognostic factors for prosthetic survival in patients operated for tumor around the knee. In the current study, we identified that the anatomical location of tumor, length of prosthetic stem, and length of bone resection during operation were significantly associated with the prosthetic survival. Basing on these factors, we also generated a graphic nomogram and a web predicting tool, which could easily applied for predicting survival probabilities of the implant at several time points.

Until now there are only a few predicting models that have been developed to help estimate the prosthetic survival probability, using independent prognostic factors.
In the studies of Zhang et al. [19], they identified the significant factors associated with the incidence of aseptic loosening after tumor prosthetic replacement around the knee, demonstrating that tumor anatomical location (proximal tibia vs. distal femur), length of prosthetic stem $(<14 \mathrm{~cm}$ vs. $>=14 \mathrm{~cm})$, and prosthetic motion mode (fixed hinge vs. rotation hinge) were independent predictors. After that, they established a graphical nomogram to help predict the risk of aseptic loosening at the time points of 5 and 10 years. This model, however, could only provide approximate risks of aseptic loosening at two points, and the applying of the model is not convenient as one need to calculate the sub-scores of the prognostic factors and the total score, and to gain the predicted survival by drawing vertical line. In the current study, we also developed a web-page based dynamic nomogram, to output a continuous survival curve, a forest plot of predicted survival and a numeric table online, being easier-to-use for clinicians and patients.

Regarding to the prognostic factors involved in our novel model, they have been widely analyzed in the previous researches [5, 20-23]. The anatomical location of the tumor at proximal tibia has been demonstrated to be associated with increased risk of implant failure compared to the tumor at distal femur in many former studies [5, 21-23]. In the study of Pala et al. [20], they reported that the failure rates of distal femoral and proximal tibia replacements were 26.7 and $36.7 \%$, but the difference was non-significant between two groups. $\mathrm{Hu}$ et al. [5] also reported that the anatomical site of tumor was associated with the implant survival of tumor 


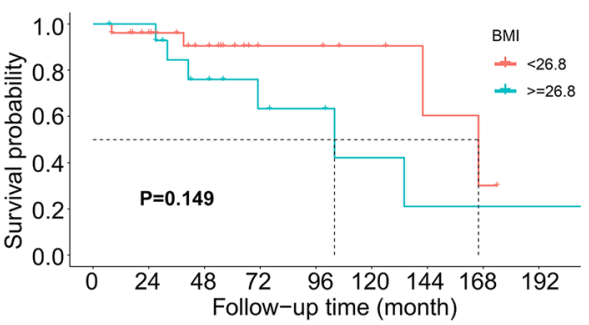

Number at risk
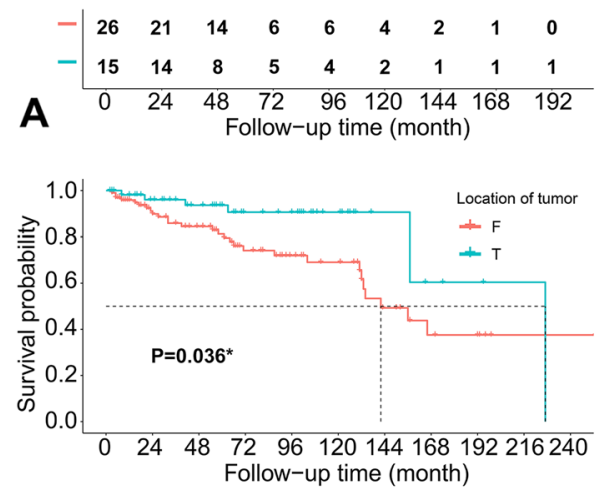

Number at risk

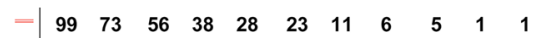

$\begin{array}{rrrrrrrrrrr}57 & 45 & 37 & 25 & 23 & 13 & 6 & 3 & 2 & 1 & 0\end{array}$

C $\quad$\begin{tabular}{lllllll}
\hline & 24 & 48 & 72 & 96 & 120144168192216240
\end{tabular} Follow-up time (month)

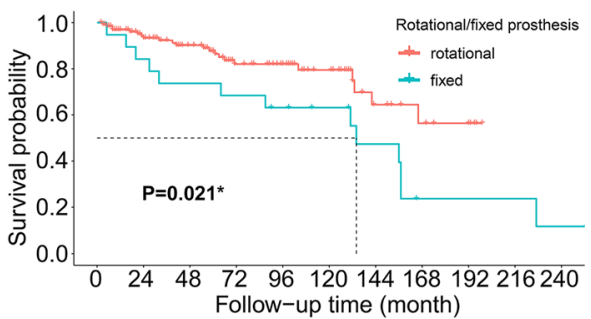

Number at risk

\begin{tabular}{l|lllllllllll}
- & 137 & 102 & 79 & 50 & 40 & 27 & 11 & 7 & 5 & 0 & 0
\end{tabular}

$\begin{array}{llllllllllll}19 & 16 & 14 & 13 & 11 & 9 & 6 & 2 & 2 & 2 & 1\end{array}$

$\begin{array}{lllllllll}0 & 24 & 48 & 72 & 96 & 120144 & 168 & 192 & 216240\end{array}$

E

Follow-up time (month)

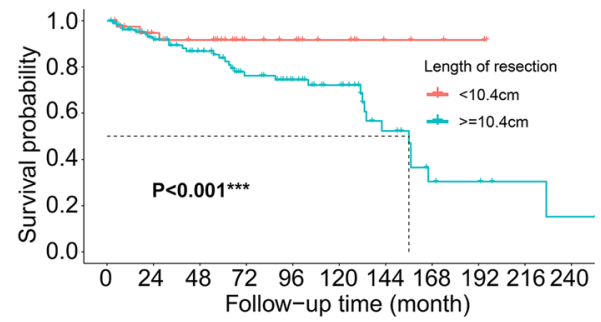

Number at risk

$\begin{array}{llllllllllll}40 & 31 & 27 & 14 & 12 & 8 & 4 & 3 & 2 & 0 & 0\end{array}$

$\begin{array}{rllllllllll}110 & 83 & 63 & 46 & 37 & 27 & 12 & 5 & 4 & 2 & 1\end{array}$

G

$\begin{array}{llllllllll}0 & 24 & 48 & 72 & 96 & 120 & 144 & 168 & 192 & 216240\end{array}$ Follow-up time (month)

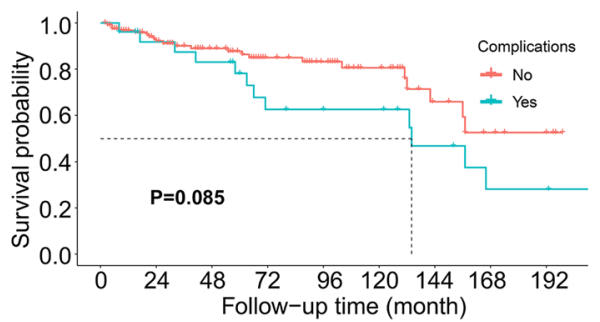

Number at risk
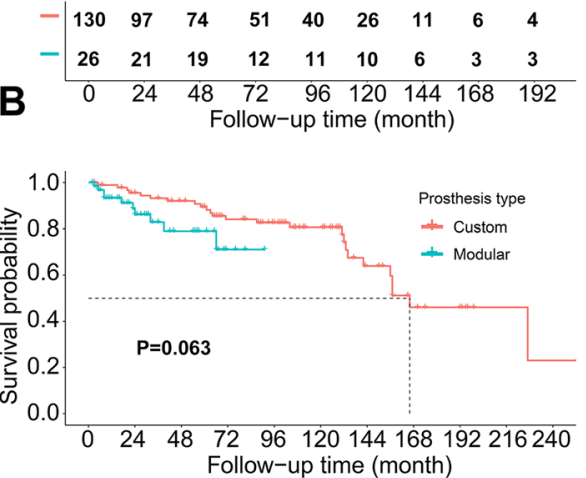

Number at risk

$\begin{array}{lllllllllll}91 & 83 & 74 & 59 & 51 & 36 & 17 & 9 & 7 & 2 & 1\end{array}$

$\begin{array}{lllllllllll}65 & 35 & 19 & 59 & 0 & 0 & 0 & 0 & 0 & 0 & 0\end{array}$

D $\quad \begin{array}{llllllllll}0 & 24 & 48 & 72 & 96 & 120 & 144 & 168 & 192 & 216240\end{array}$ Follow-up time (month)

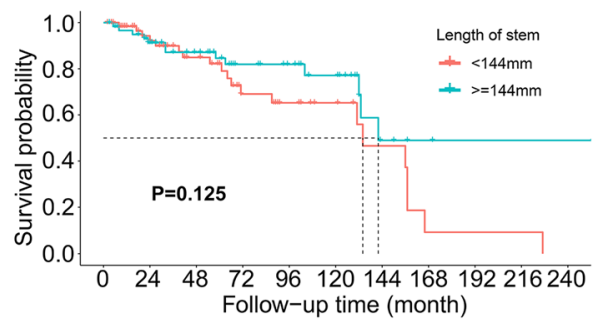

Number at risk

\begin{tabular}{l|lllllllllll}
- & 66 & 44 & 32 & 18 & 13 & 9 & 5 & 1 & 1 & 1 & 0
\end{tabular}

$\begin{array}{llllllllllll}- & 61 & 49 & 39 & 26 & 20 & 15 & 4 & 2 & 1 & 1 & 1\end{array}$

$\begin{array}{lllllllll}0 & 24 & 48 & 72 & 96 & 120144 & 168192216240\end{array}$

F Follow-up time (month)

Fig. 4 Kaplan-Meier survival curves for prognostic factors significantly associated with prosthetic survival, according to univariate COX analysis 
Forest plot for multivariate COX analysis

\begin{tabular}{|c|c|c|c|c|}
\hline Variables & & & $\mathrm{HR}(95 \% \mathrm{Cl})$ & $p$ value \\
\hline BMI & & $\square$ & $9.74(0.68,140.16)$ & 0.0942 \\
\hline operation related complications & & $\square$ & $1.48(0.65,3.36)$ & 0.3449 \\
\hline anatomical location & $\square$ & & $0.42(0.20,0.89)$ & $0.0242^{*}$ \\
\hline custom/modular prosthesis & & $\square$ & $1.83(0.65,5.16)$ & 0.2512 \\
\hline rotational/fixed prosthesis & & $\square$ & $1.45(0.59,3.53)$ & 0.4182 \\
\hline length of prosthetic stem & $\square$ & & $0.44(0.19,0.99)$ & $0.0479^{*}$ \\
\hline length of resection & & $\square$ & $11.08(3.34,36.78)$ & $<0.001^{* * *}$ \\
\hline
\end{tabular}

Fig. 5 Forest plot displaying the effect sizes of prognostic factors involved in multivariate COX analysis

prosthesis around knee. Zhang et al. [21] investigated the prognosis value of site of the implant, and they reported a slight difference on the 5-year prosthetic survival $(86.1 \%$ at distal femur and $66.9 \%$ at proximal tibia, $p=0.09$ ). Guo et al. [22] identified the independent risk factors for implant failure in patients operated for tumor around the knee, and the result of multivariate COX analysis presented that the prosthesis implanted at the proximal tibia was associated with increased failure risk, when compared to that of the distal femur. Mazaleyrat et al. [23] reported that the 5-year and 10-year survival rates of implant were 84 and $70 \%$ for tumor located at

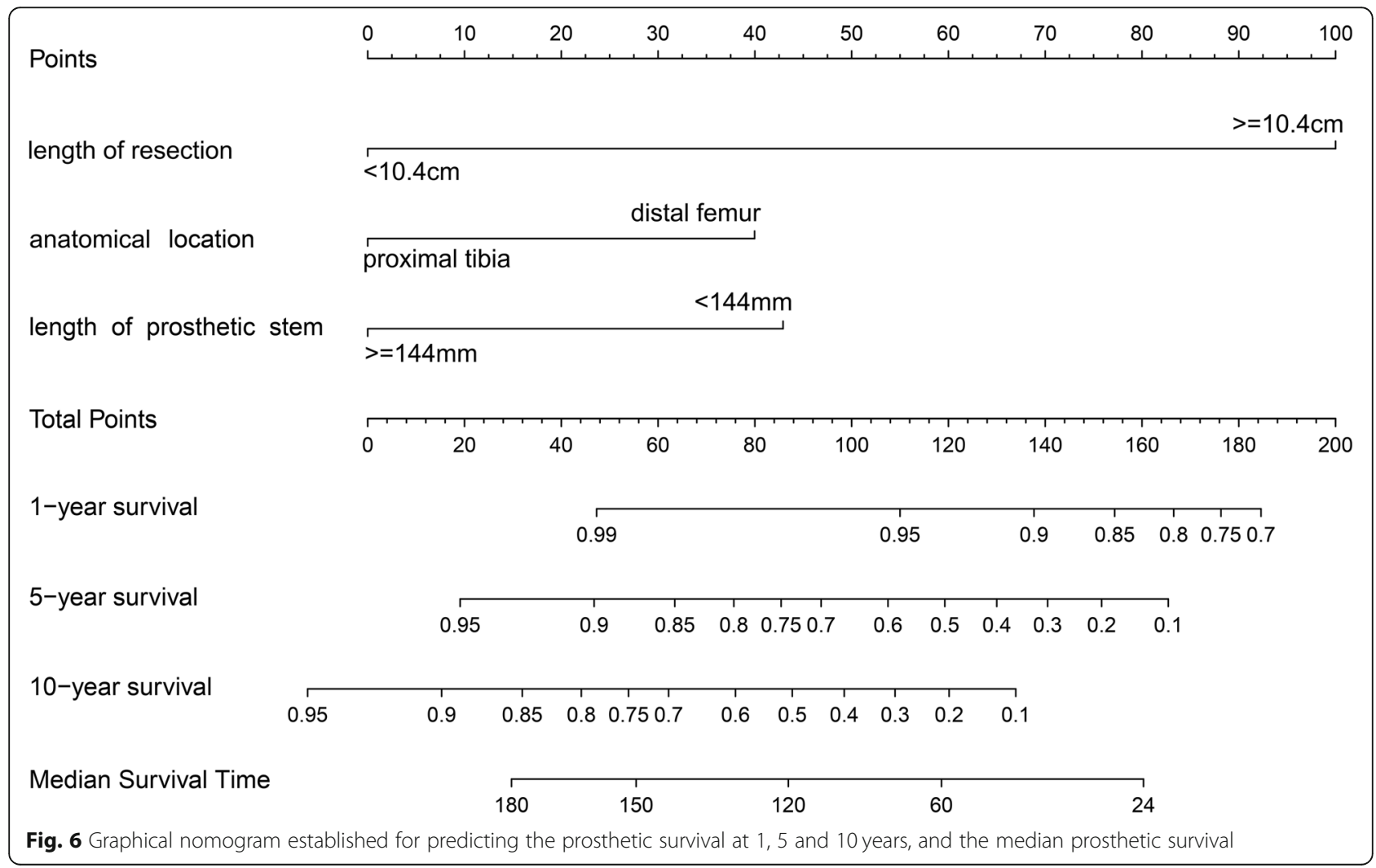



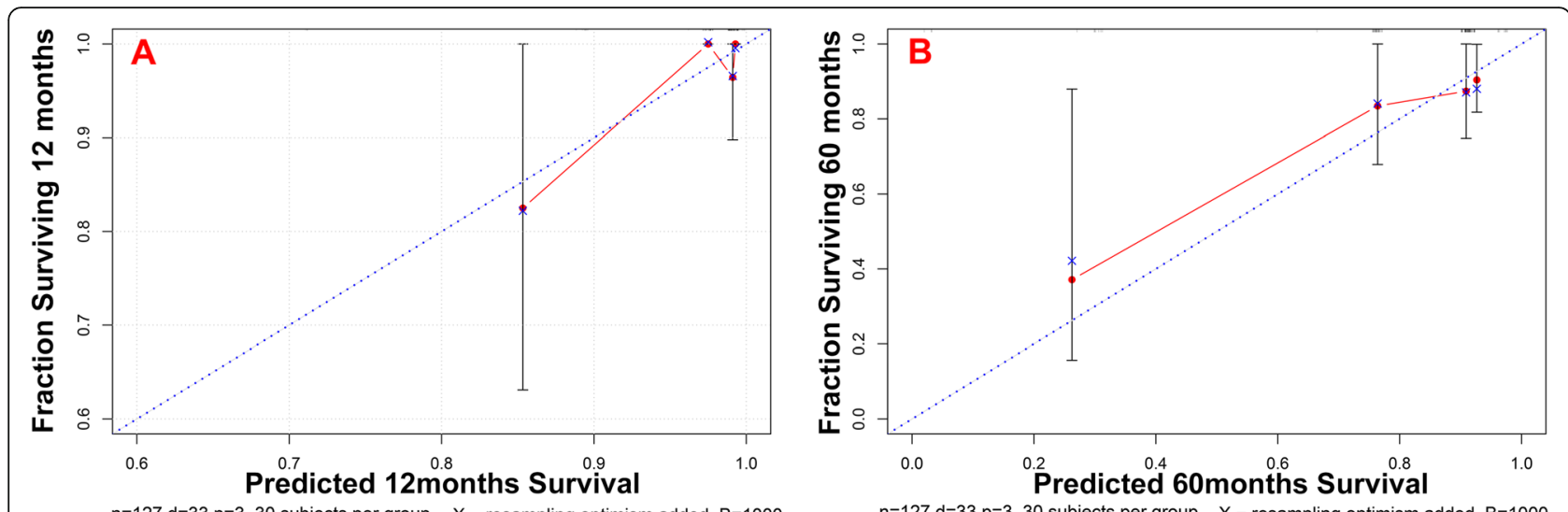

$n=127 d=33 p=3,30$ subjects per group $\quad X-$ resampling optimism added, $B=1000$ $n=127 d=33 p=3,30$ subjects per group $\quad X$ - resampling obsed on observed -predicted
Gray ideal

$n=127 d=33 p=3,30$ subjects per group $\quad X-$ resampling optimism added, $B=1000$ Gray: ideal Based on observed-predicted
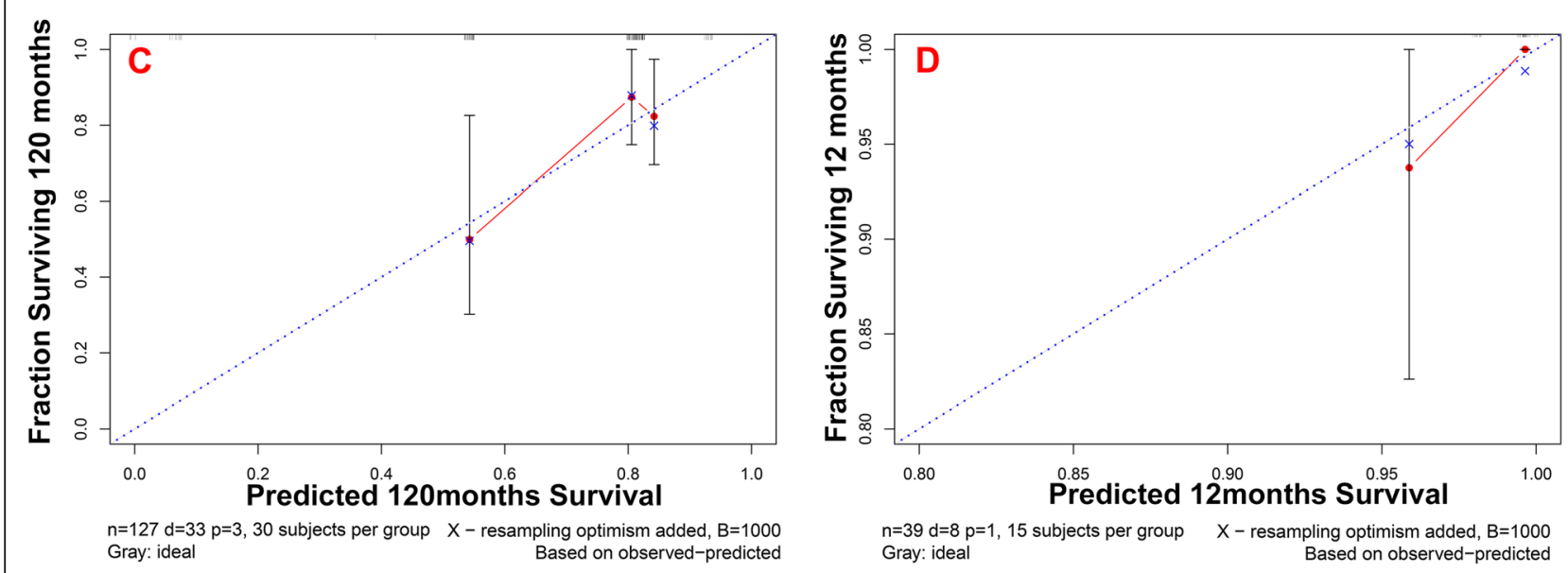

$n=39 d=8 p=1,15$ subjects per group $\quad X$ - resampling optimism added, $B=1000$ Gray: ideal Based on observed-predicted
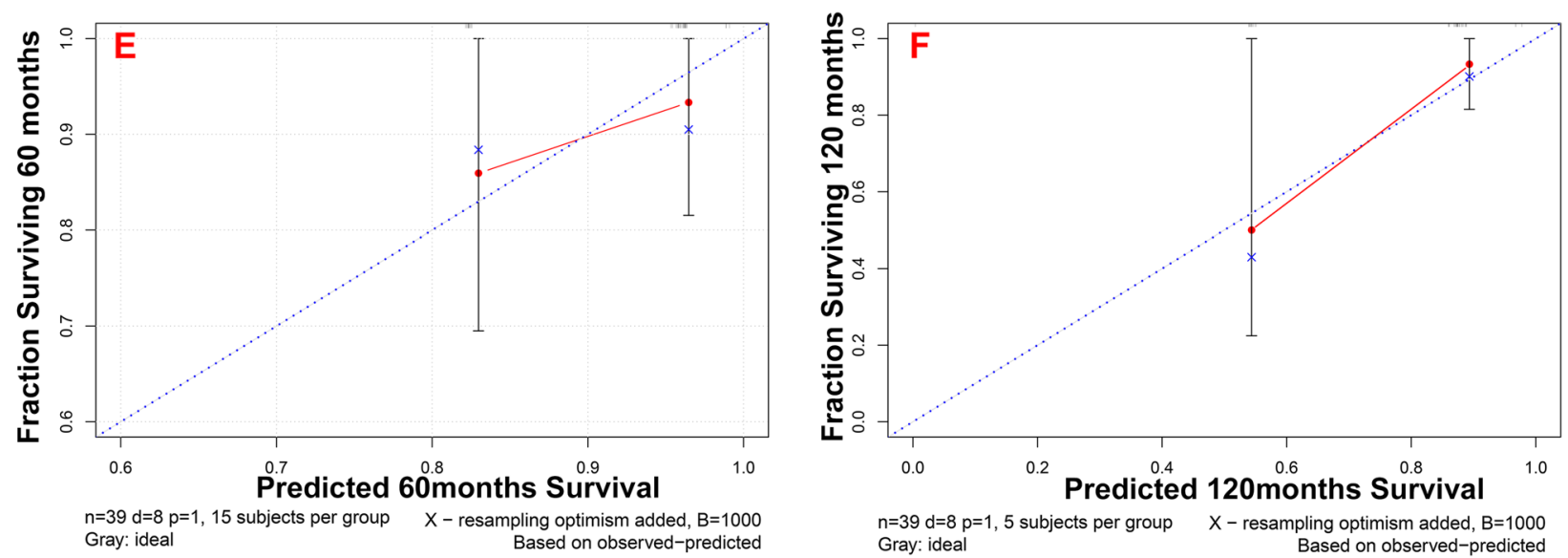

Fig. 7 Calibration curves for evaluating the consistency between the predicted and actual survival probabilities, both in training and validation samples, at time points of 1, 5 and 10 years. Generally, satisfactory consistencies between predicted and actual survival rates were demonstrated

distal femur, while 74 and $43 \%$ for tumor located at proximal tibia, being significantly different between the two groups by log-rank test $(p=0.02)$. Our result about the prognostic effect of anatomical location of tumor was in accordance with these previous researches. It could be speculated that the poor soft tissue coverage, difficulties with anchoring the patellar tendon and possible injuries to the neurovascular system are the most likely causes for this difference.

Length of prosthetic stem was another important predictor for the implant failure, in several published articles [19, 24, 25]. Bergin et al. [24] evaluated the 


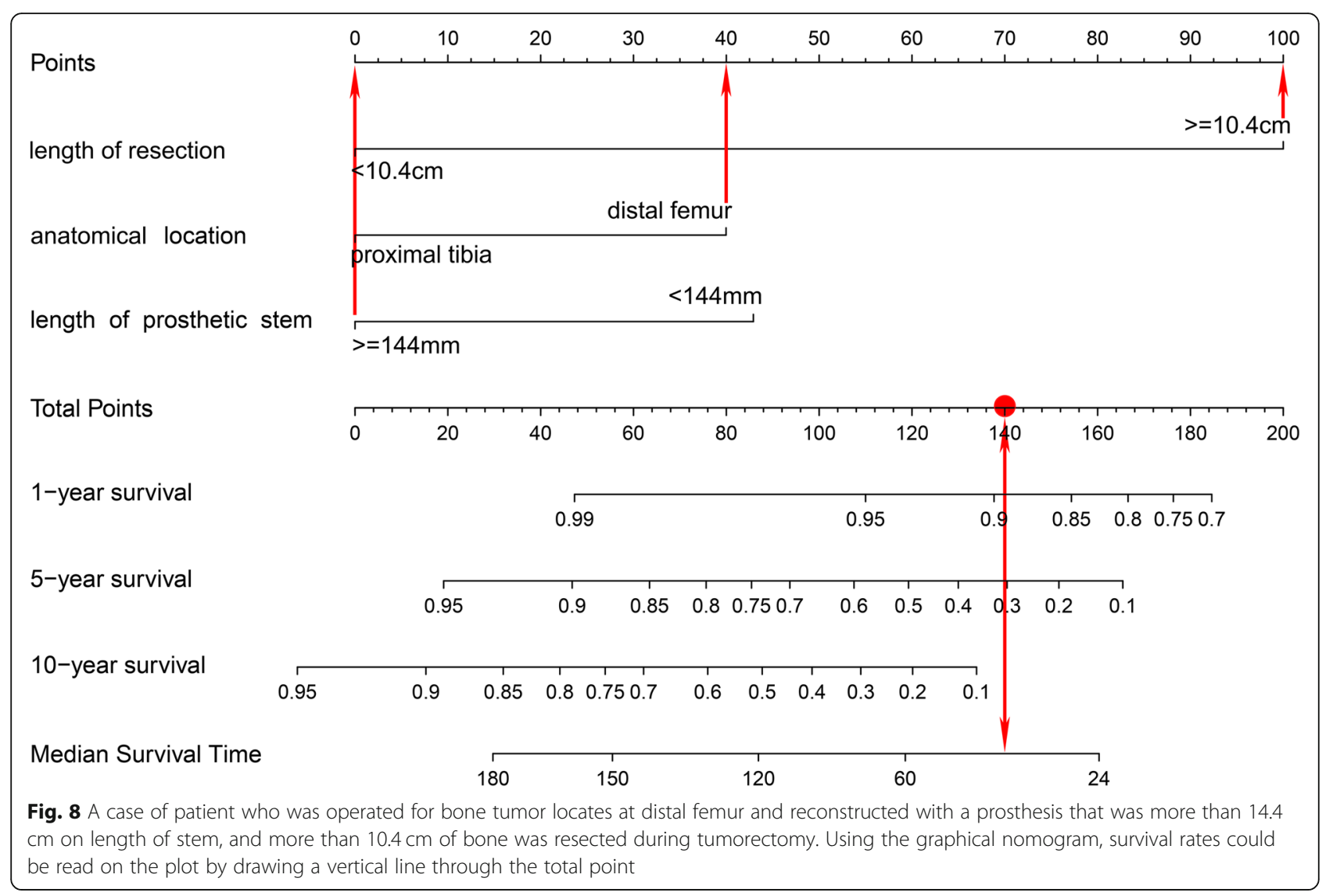

influences of the diameter of prosthetic stem and length ratio of bone:stem on the incidence of aseptic loosening in distal femoral endoprostheses, and they found that patients with stable implants had significantly larger stem sizes and lower bone:stem ratios than those with loose implants. Zhang et al. [19] established a predicting nomogram for aseptic loosening after tumor prosthetic replacement around the knee, and they identified that the length of the prosthetic stem was independent prognostic factor, being included in their novel prediction model. This suggests that longer stem of the endoprostheses may have a mechanical advantage by obtain more osteointergration between the bone and the endoprosthesis, to prevent the early failures.

Resection length during tumorectomy was also recognized as an independent prognostic factor for prosthetic survival in former studies [5, 22, 24, 26, 27]. Guo et al. [22] found that a resection length of $14 \mathrm{~cm}$ or more was significant negative prognostic factor for endopristhetic replacement for primary tumors around the knee. Hu et al. [5] reviewed the published articles about application of artificial prosthesis reconstruction techniques in malignant tumors around the knee joint, showing that the longer the neoplastic bone resected, the worse the prosthetic survival rate is. Wu et al. [26] identified the prognostic effect of several factors, including the patient age, surgical stage, design of implant (custom vs. modular), stem diameter, and resection length, through multivariate COX analysis, demonstrating that design of prosthesis and length of resection were significantly associated with prosthetic survival. Kawai et al. [27] reported 82 cases of artificial prosthesis reconstruction after resection of distal femur malignant bone tumors. The prosthetic survival rate of the group in whom $<40 \%$ of the distal femur length was resected was considerably higher than that of the group with resection lengthmore than $40 \%$, according to multivariate analysis. In our study, we divided the patients into two group by the cutoff point detected with running log-rank test, and found that patients with more than $10.4 \mathrm{~cm}$ of resection length was associated with increased implant failure. The influence of the extent of bone resections on the development of implant failure may be contributed by the increased torque production out of the line of prosthesis and/or impairment of quadriceps contraction. Changes in biomechanical stresses after extensive resections of bone and adjacent muscles probably are the reasons for the increased failure incidence of these implants.

This study, nevertheless, is of several limitations. Firstly, this study was designed as a retrospective cohort study, causing inevitable risk of bias on collection of the data. Thus, some more prospective and long-term 


\section{Dynamic Nomogram (Author: Pang CG)}

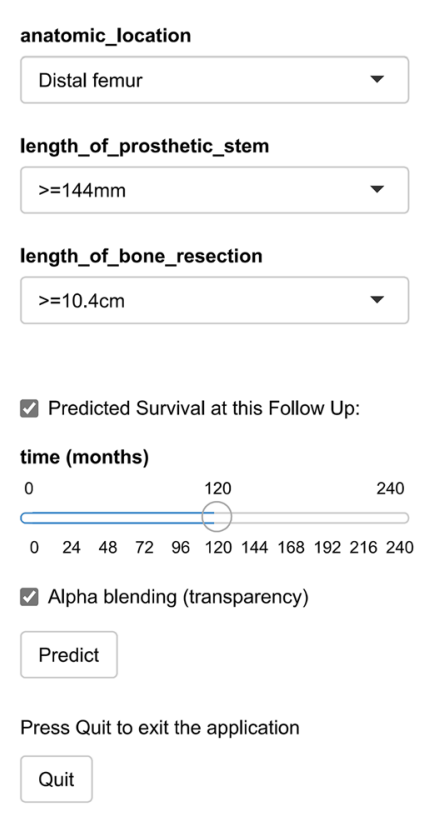

Survival plot
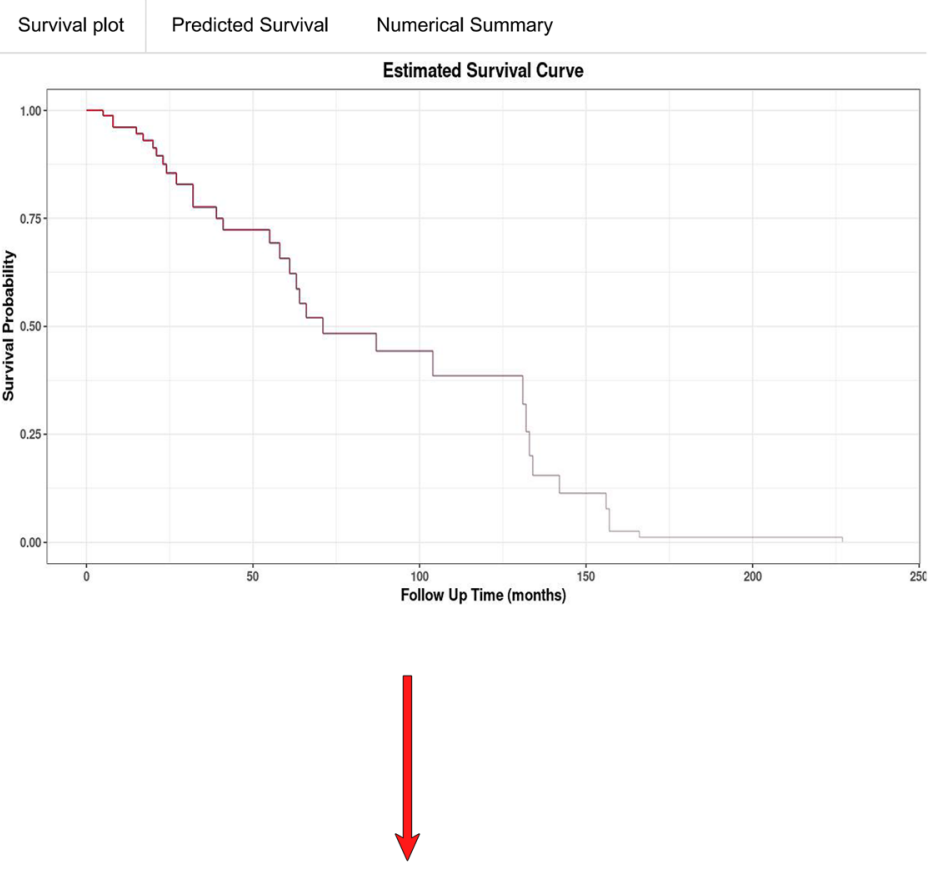

Numerical Summary

\section{5\% Confidence Interval for Survival Probability $\mathbb{Q}+\ldots$}

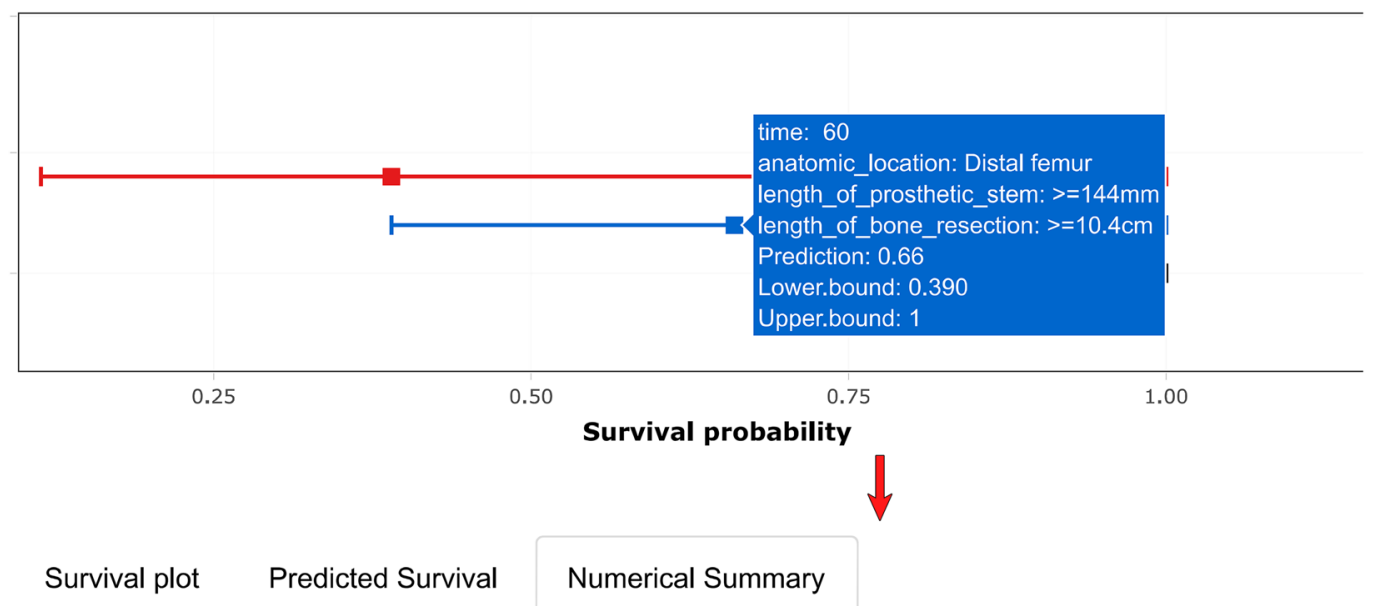

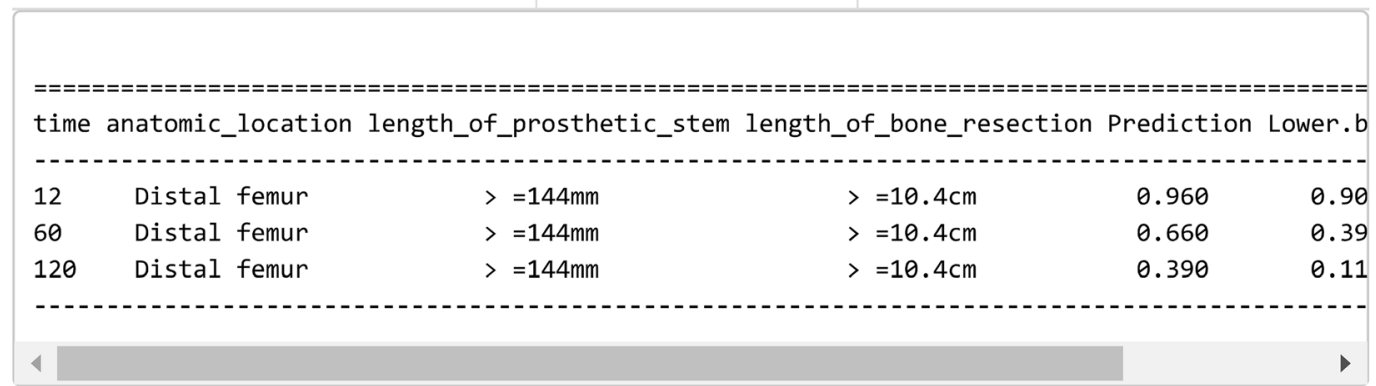

Fig. 9 A case of patient who was operated for bone tumor locates at distal femur and reconstructed with a prosthesis that was more than $14.4 \mathrm{~cm}$ on length of stem, and more than $10.4 \mathrm{~cm}$ of bone was resected during tumorectomy. Through the webpage-based dynamic nomogram, the detailed prosthetic survival probabilities at 12,60 and 120 months could be automatically calculated, which is shown to be $0.890,0.305$ and 0.068 , respectively 
cohort studies or randomized controlled trials should be conducted to clarified the prognostic effect of the predicting factors identified in this study. Secondly, as only a few patients were provided with uncemented prostheses in our institutions, it was impossible to take full assessment on the prognostic effect of the fixation method for the endoprostheses. Thus, we excluded patients reconstructed by implants without cement fixation to minimize the risk of bias caused by fixation methods. Thirdly, the patients used for external validation was sampled from the same cohort as the training sample used for model developing. Hence, further external validation using sample from different clinical centers or even different countries is necessary. Finally, it is difficult to collect large sample size in this topic due to the low frequency of tumor resection and endoprosthetic reconstruction for tumor around knee. Thus, to ensure the statistical power in the regression analysis and model developing, most participants were put in the training sample, causing the relative small size of validation sample.

\section{Conclusions}

The anatomical location of the endoprostheses, length of the prosthetic stem and the length of the bone resection were demonstrated to be significantly associated with the risk of implant failure in patients reconstructed for tumors around the knee. A graphical nomogram and a user-interactive online dynamic nomogram were developed to help clinicians and patients easily predict the survival probabilities of implant at any time point postoperatively.

\section{Abbreviations}

CPM: continuous passive motion; BMI: body mass index; Cl: confidence interval; HR: hazard ratio; MRI: magnetic resonance imaging; MSCT: Multi Slice Computerized Tomography; MSTS: Musculoskeletal Tumor Society; TRIPOD: Transparent Reporting of a Multivariable Prediction Model for Individual Prognosis or Diagnosis

\section{Supplementary Information}

The online version contains supplementary material available at https://doi. org/10.1186/s12885-021-08710-x.

Additional file 1.

\section{Acknowledgements}

Not applicable.

\section{Authors' contributions}

PCG and HYC conceived of and designed the study, performed the analysis, interpreted the results and wrote the manuscript. YXG performed the revision and validation of the manuscript. ZYL and LYC performed the data collection and analysis. All authors read and approved the final manuscript.

\section{Funding}

This research did not receive any specific grant from funding agencies in the public, commercial, or not-for-profit sectors.

\section{Availability of data and materials}

The datasets used and/or analyzed during the current study are available from the corresponding author on reasonable request.

\section{Declarations}

Ethics approval and consent to participate

This study was performed according to the "Declaration of Helsinki" (as revised in 2013) and was approved by the ethics committee of Tianjin Hospital. Informed consent was waived by the Institutional Ethics Committee of Tianjin Hospital because of the retrospective nature of this study.

\section{Consent for publication}

Not applicable.

\section{Competing interests}

The authors declare that they have no competing interests.

\section{Author details}

${ }^{1}$ Graduate School, Tianjin Medical University, Tianjin 300070, China.

${ }^{2}$ Department of Orthopedic Surgery, Huashan Hospital, Fudan University, No. 12 Wulumugi Road, Shanghai 200040, China. ${ }^{3}$ Department of Bone Tumor of Tianjin Hospital, Tianjin 300211, China.

Received: 23 October 2020 Accepted: 18 August 2021

Published online: 03 September 2021

\section{References}

1. Zhang X, Wang Z. A statistic analysis of 3409 cases of tumors and tumorlike lesions of bones and joints. Chinese J Bone Tumor Bone Dis. 2010;9(3):189-95.

2. Henderson ER, Groundland JS, Pala E, Dennis JA, Wooten R, Cheong D, et al. Failure mode classification for tumor endoprostheses: retrospective review of five institutions and a literature review. J Bone Joint Surg Am. 2011;93(5): 418-29. https://doi.org/10.2106/JBJS.J.00834.

3. Allison DC, Carney SC, Ahlmann ER, Hendifar A, Chawla S, Fedenko A, et al. A meta-analysis of osteosarcoma outcomes in the modern medical era. Sarcoma. 2012;2012:704872.

4. Kotz Rl. Progress in musculoskeletal oncology from 1922-2012. Int Orthop 2014:38(5):1113-1122, Progress in musculoskeletal oncology from 1922 2012, DOl: https://doi.org/10.1007/s00264-014-2315-0.

5. Hu YC, Lun DX. Application of artificial prosthesis reconstruction techniques in malignant tumors around the knee joint. Orthop Surg. 2012:4(1):1-10. https://doi.org/10.1111/j.1757-7861.2011.00161.x.

6. Ahlmann ER, Menendez LR, Kermani C, Gotha H. Survivorship and clinical outcome of modular endoprosthetic reconstruction for neoplastic disease of the lower limb. J Bone Joint Surg Br. 2006:88:790-5.

7. Mirra JM, Picci P, Gold RH, eds. Bone Tumors: Clinical, Radiologic and Pathologic Correlations. Vol. 1. Philadelphia: Lea \& Febiger; 1989:248-62.

8. Ruggieri P, Bosco G, Pala E, Errani C, Mercuri M. Local recurrence, survival and function after total femur resection and megaprosthetic reconstruction for bone sarcomas. Clin Orthop Relat Res. 2010;468(11):2860-6. https://doi. org/10.1007/s11999-010-1476-4

9 Gaur AH, Liu T, Knapp KM, Daw NC, Rao BN, Neel MD, et al. Infections in children and young adults with bone malignancies undergoing limbsparing surgery. Cancer. 2005;104(3):602-10. https://doi.org/10.1002/ cncr.21212.

10. Gitelis S, Yergler J, Sawlani N, Schiff A, Shott S. Short and long term failure of the modular oncology knee prosthesis. Orthopedics. 2008;31:362.

11. Sim IW, Tse LF, Ek ET, Powell GJ, Choong PF. Salvaging the limb salvage: management of complications following endoprosthetic reconstruction for tumors around the knee. Eur J Surg Oncol. 2007;33(6):796-802. https://doi. org/10.1016/j.ejso.2006.10.007.

12. Shehadeh A, Noveau J, Malawer M, Henshaw R. Late complications and survival of endoprosthetic reconstruction after resection of bone tumors. Clin Orthop Relat Res. 2010;468(11):2885-95. https://doi.org/10.1007/s11999010-1454-x.

13. Unwin PS, Cannon SR, Grimer RJ, Kemp HB, Sneath RS, Walker PS. Aseptic loosening in cemented custom-made prosthetic replacements for bone tumours of the lower limb. J Bone Joint Surg Br. 1996;78:5-13. 
14. Wirganowicz PZ, Eckardt JJ, Dorey FJ, Eilber FR, Kabo JM. Etiology and results of tumor endoprosthesis revision surgery in 64 patients. Clin Orthop Relat Res. 1999;358:64-74.

15. Collins GS, Reitsma JB, Altman DG, Moons KG. Transparent reporting of a multivariable prediction model for individual prognosis or diagnosis (TRIPOD): the TRIPOD State-13; 2015.

16. Enneking WF, Dunham W, Gebhardt MC, Malawar M, Pritchard DJ. A system for the functional evaluation of reconstructive procedures after surgical treatment of tumors of the musculoskeletal system. Clin Orthop Relat Res. 1993;286:241-6.

17. Facciorusso A, Prete VD, Crucinio D, Serviddio G, Vendemiale G, Muscatiello N. Lymphocyte-to-monocyte ratio predicts survival after radiofrequency ablation for colorectal liver metastases. World J Gastroenterol. 2016;22(16): 4211-8. https://doi.org/10.3748/wjg.v22.116.4211.

18. Facciorusso A, Prete VD, Antonino M, Neve V, Crucinio N, Di Leo A, et al. Serum ferritin as a new prognostic factor in hepatocellular carcinoma patients treated with radiofrequency ablation. J Gastroenterol Hepatol. 2014; 29(11):1905-10. https://doi.org/10.1111/jgh.12618.

19. Zhang HR, Zhao YL, Wang F, Yang XG, Xu MY, Qiao RQ, et al. Establishment and validation of a nomogram model for periprosthetic infection after megaprosthetic replacement around the knee following bone tumor resection: a retrospective analysis. Orthop Traumatol Surg Res. 2020;106(3): 421-7. https://doi.org/10.1016/j.otsr.2019.10.023.

20. Pala E, Trovarelli G, Calabrò T, Angelini A, Abati CN, Ruggieri P. Survival of modern knee tumor Megaprostheses: failures, functional results, and a comparative statistical analysis. Clin Orthop Relat Res. 2015:473(3):891-9. https://doi.org/10.1007/s1 1999-014-3699-2

21. Zhang C, Hu J, Zhu K, Cai T, Ma X. Survival, complications and functional outcomes of cemented megaprostheses for high-grade osteosarcoma around the knee. Int Orthop. 2018;42(4):927-38. https://doi.org/10.1007/s002 64-018-3770-9.

22. Guo W, Ji T, Yang R, Tang $X$, Yang Y. Endoprosthetic replacement for primary tumours around the knee: experience from Peking University. J Bone Joint Surg Br. 2008;90:1084-9.

23. Mazaleyrat M, Nail LL, Auberger G, Biau D, Rosset P, Waast D, et al. Survival and complications in hinged knee reconstruction prostheses after distal femoral or proximal tibial tumor resection: a retrospective study of 161 cases. Orthop Traumatol Surg Res. 2020;106(3):403-7. https://doi.org/10.101 6/.otsr.2019.11.027.

24. Bergin PF, Noveau JB, Jelinek JS, Henshaw RM. Aseptic loosening rates in distal femoral Endoprostheses: does stem size matter? Clin Orthop Relat Res. 2012;470(3):743-50. https://doi.org/10.1007/s11999-011-2081-X.

25. Bus MA, van de Sande MAJ, Fiocco M, Schaap GR, Bramer JAM, Dijkstra PDS. What are the long-term results of MUTARS modular Endoprostheses for reconstruction of tumor resection of the distal femur and proximal tibia? Clin Orthop Relat Res. 2017:475(3):708-18. https://doi.org/10.1007/s11999-01 5-4644-8.

26. Wu CC, Henshaw RW, Pritsch T, Squires MH, Malawer MM. Implant design and resection length affect cemented Endoprosthesis survival in proximal Tibial reconstruction. J Arthroplast. 2008;23(6):886-93. https://doi.org/10.101 6/j.arth.2007.07.007.

27. Kawai A, Lin PP, Boland PJ, Athanasian EA, Healey JH. Relationship between magnitude of resection, complication, and prosthetic survival after prosthetic knee reconstructions for distal femoral tumors. J Surg Oncol. 1999;70(2):109-15. https://doi.org/10.1002/(SICl)1096-9098(199902)70:2< 109::AID-JSO9>3.0.CO;2-X.

\section{Publisher's Note}

Springer Nature remains neutral with regard to jurisdictional claims in published maps and institutional affiliations.

Ready to submit your research? Choose BMC and benefit from:

- fast, convenient online submission

- thorough peer review by experienced researchers in your field

- rapid publication on acceptance

- support for research data, including large and complex data types

- gold Open Access which fosters wider collaboration and increased citations

- maximum visibility for your research: over $100 \mathrm{M}$ website views per year

At BMC, research is always in progress.

Learn more biomedcentral.com/submissions 